\title{
EL PLURALISMO COMO FUNDAMENTO DE LA EDUCACIÓN MULTICULTURAL
}

\section{Antonio Tirso Ester Sánchez ${ }^{1}$}

\section{Resumen}

Un intento de aproximación conceptual del derecho a la educación nos hace comprobar que su proyección puede analizarse desde una vertiente multidimensional, ya que con independencia del carácter subjetivo con el que cuenta, no debe ser óbice para eliminar los problemas que presenta las virtualidades de la educación. Este trabajo pretende evidenciar la importancia del reconocimiento universal del derecho a la educación como herramienta que debe estar garantizada por el Estado y las políticas públicas sin ninguna discriminación. La diferenciación cultural y axiológica que presentan las sociedades multiculturales es una realidad que debe estar presente en cualquier proyecto educativo de toda sociedad democrática, posibilitando vehicular las posibles diferencias a través de políticas públicas inspiradas en el pluralismo educativo.

Palabras clave: Educación multicultural. Pluralismo educativo. Valores axiológicos. Diversidad cultural.

\section{PLANTEAMIENTO}

La consideración que defiende el derecho a la educación como un auténtico derecho subjetivo, parte del ideal que el Estado, a través de la configuración y puesta en practica de las políticas públicas en materia educativa, debe asumirlo como un objetivo y garantizarlo a los educandos ${ }^{2}$. Desde esta perspectiva, la proyección del derecho a la educación viene a ser entendida como una exigencia básica, cuyo contenido fundamental comprende "el derecho de los menores de ser educados conforme a las determinaciones de sus padres o tutores y supletoriamente conforme a las de los poderes públicos competentes, el derecho a la libre elección de centros educativos distintos de los públicos en todos los niveles de la enseñanza, el derecho de los padres y tutores a que sus hijos o pupilos reciban en la enseñanza la formación religiosa y moral que esté de acuerdo con sus propias convicciones, el derecho a que el sistema educativo y los establecimientos de enseñanza no sean discriminatorios, el derecho a la financiación pública de la enseñanza obligatoria y el derecho a la ayuda económica de los poderes públicos en los niveles de enseñanza no obligatoria con un criterio de igualdad de trato”3.

\footnotetext{
${ }^{1}$ Doutor em Direito, Professor de filosofia do direito e do Máster Universitario en Abogacía da Universidad de Las Palmas de Gran Canaria, Espanha. E-mail: tirso.ester@ulpgc.es

2 FERNÁNDEZ-MIRANDA CAMPOAMOR, Alfonso. "Comentarios al artículo 27 CE”. Comentarios a la Constitución Española de 1978. Tomo III. Madrid: Edersa Cortes Generales, 1996, p. 171.

${ }^{3}$ MARTÍNEZ LÓPEZ-MUNíZ, José Luis. "La educación en la Constitución española: derechos fundamentales y libertades públicas en materia de enseñanza”. Persona y derecho, núm. 6, 1979, pp. 234-268.
} 
Esa igualdad de trato tiene como respuesta lógica la problemática en cuanto a la delimitación del contenido, puesto que es precisamente la formación en valores y la implicación axiológica, que se deriva de la misma, la que pone de manifiesto la precisión implícita del derecho a la educación. Así mismo, la problemática en torno a la precisión aumenta cuando el mismo derecho a la educación concreta la asunción del reconocimiento de otros derechos como pudiera ser el derecho el derecho a la enseñanza sin más limitaciones que las reconocidas por el ordenamiento jurídico 4 .

Cabe destacar, en este sentido, lo contemplado por el artículo 13.1 de la Constitución española cuando garantiza los derechos y las libertades públicas de los extranjeros en España reconocidos en el Título Primero del texto constitucional. De la interpretación de este precepto constitucional, no puede entenderse como un derecho que resulte una limitación a los sujetos extranjeros. En esta línea, la Convención relativa a la lucha contra las discriminaciones en la esfera de la enseñanza, se reconoce expresamente en su artículo 3.e) que "los Estados Partes se comprometen a conceder a los súbditos extranjeros residentes en su territorio, el acceso a la enseñanza en las mismas condiciones que a sus propios nacionales".

También el Pacto Internacional de Derechos Económicos, Sociales y Culturales, contempla en su artículo 13.1 que "los Estados Partes en el presente Pacto reconocen el derecho de toda persona a la educación. Convienen en que la educación debe orientarse hacia el pleno desarrollo de la personalidad humana y del sentido de su dignidad, y debe fortalecer el respeto por los derechos humanos y las libertades fundamentales. Convienen asimismo en que la educación debe capacitar a todas las personas para participar efectivamente en una sociedad libre, favorecer la comprensión, la tolerancia y la amistad entre todas las naciones y entre todos los grupos raciales, étnicos o religiosos, y promover las actividades de las Naciones Unidas en pro del mantenimiento de la paz".

Este reconocimiento desde el punto de vista de la titularidad, parte del ideal del derecho a la educación como un auténtico derecho universal. Precisamente por ello, desde este trabajo se refuerza la idea de inclusión a todos los sectores poblacionales, con independencia que ostenten una cultura identitaria diferente a la población de acogida o grupo mayoritario, posibilitando tal y como defiende el profesor De Lucas, "compensar los efectos negativos derivados de la pertenencia al grupo minoritario, asegurando la igualdad en el reconocimiento y en la garantía de derechos, y asegurar la participación en la vida pública de estas minorías en condiciones de igualdad”’

Resulta destacable, en este sentido, lo contemplado por la Declaración Universal de los Derechos Humanos en su artículo 26 donde se reconoce que "toda persona tiene derecho a la educación. La educación debe ser gratuita, al menos en lo concerniente a la instrucción elemental y fundamental. La instrucción elemental

\footnotetext{
${ }^{4}$ EMBID IRUJO, Antonio. "El contenido del derecho a la educación”. Revista Española de Derecho Administrativo, núm. 31, 1981, pp. 654 y ss.

5 DE LUCAS, Javier. "El vínculo social, entre ciudadanía y cosmopolitismo”. El vínculo social: ciudadanía y cosmopolitismo, Valencia: Tirant lo Blanch, 2002, pp. 26-27.
} 
será obligatoria. La instrucción técnica y profesional habrá de ser generalizada; el acceso a los estudios superiores será igual para todos, en función de los méritos respectivos. La educación tendrá por objeto el pleno desarrollo de la personalidad humana y el fortalecimiento del respeto a los derechos humanos y a las libertades fundamentales; favorecerá la comprensión, la tolerancia y la amistad entre todas las naciones y todos los grupos étnicos o religiosos; y promoverá el desarrollo de las actividades de las Naciones Unidas para el mantenimiento de la paz. Los padres tendrán derecho preferente a escoger el tipo de educación que habrá de darse a sus hijos".

No se puede obviar que derecho a la educación se encuentra íntimamente relacionado con la idea de libertad. El profesor Martínez López-Muñiz no pasa por alto este planteamiento cuando afirma que el derecho a la educación "no solo entraña las facultades de una libertad de hacer o de no hacer o de cómo hacer, sino también y sobre todo un poder de exigir a otros unas prestaciones positivas dirigidas a producir el resultado de la instrucción educativa”. Por tanto, la importancia del derecho a la educación no sólo se proyecta como herramienta, sino también como una garantía para que el educando alcance un mayor grado de autonomía personal.

\section{LA PROBLEMÁTICA AXIOLÓGICA EN LA EDUCACIÓN MULTICULTURAL}

En la actualidad, la sociedad multicultural ${ }^{7}$ reivindica un replanteamiento en cuanto a las exigencias debidas en torno a los valores interculturales que presiden en las diferentes comunidades sociales. En ese sentido, el profesor Aznar Minguet reconoce que el fenómeno de la globalización presente en los diferentes ámbitos de actividad humana está planteando en las sociedades actuales la necesidad de "afirmar la diversidad cultural, y va a requerir que las instituciones educativas insertas en sociedades pluriculturales, afirmen la realidad de la diversidad cultural local, desde la consideración de la unidad global esencial de lo humano" ${ }^{8}$. Ello lleva implícito necesariamente un avance en las políticas educativas ${ }^{9}$ que partan de la base del reconocimiento de una educación intercultural capaz de potenciar las garantías de igualdad ante la diversidad en los diferentes valores culturales.

Se defiende por tanto desde este estudio, que la estructuración del sistema educativo deberá atender a los valores y principios implícitos en los textos constitucionales y el ideal declarado sobre la universalidad de los

\footnotetext{
${ }^{6}$ MARTÍNEZ LÓPEZ-MUÑÍZ, José Luis. Op. cit., p.37.

${ }^{7}$ PEIRÓ I GREGÓRI, Salvador. "Multiculturalidad y valores de convivencia educativa”. Multiculturalidad escolar y convivencia educativa. Madrid: ECU, 2008, p. 92, argumenta que "la multiculturalidad no sería tanto la convivencia de personas pertenecientes a diversas subculturas, cuanto a la presencia simultánea en las coordenadas espacio-temporales de sujetos con identidades culturales que no se pueden superponer".

${ }^{8}$ AZNAR MINGUET, Pilar.; "Criterios pedagógicos y retos educativos para abordar la integración de inmigrantes en la escuela". Multiculturalidad escolar y convivencia educativa. Madrid: ECU, 2008, p. 27.

${ }^{9}$ MUÑOZ ARNAU, Juan Antonio. Derechos y libertades en la política y la legislación educativas españolas. Navarra: Universidad de Navarra, 2010, p. 42, entiende por políticas educativas como aquellas "actividades estatales de gobierno (....) que, con base en las disposiciones constitucionales, tienen por objeto establecer las normas reguladoras de los procesos educativos, crear las instituciones correspondientes ( ....) y dotarlas de los medios personales y materiales, para satisfacer el derecho fundamental a la educación”.
} 
Derechos Humanos. Ahora bien, la consideración de estos valores y principios no puede realizarse en abstracto sin más, sino que tendrá que atenderse también a las peculiares circunstancias de cada momento y de cada lugar. Eusebio Fernández lo pone de manifiesto al señalar que, al margen de estos valores constitucionales, es conveniente incluir "nuevos elementos que se encuentran en el horizonte político y cultural y que deben instarnos a ampliar nuestras perspectivas valorativas para definirlas y adaptarlas, y, también, a meter otras nuevas. Así, fenómenos como la globalización, los movimientos migratorios o la multiculturalidad de las sociedades deben tener adecuadas respuestas en un programa de educación moral, cívica y política" ${ }^{10}$.

Así lo defiende también la profesora Santana cuando reconoce que "una de las premisas por las cuales un individuo pueda entender su entorno cercano seguro y cómodo en una adaptación a la vida social en general, debe partir, en principio, porque se sienta no solamente libre, sino respetado en sus valores, en sus costumbres, en definitiva, en su cultura identitaria" ${ }^{11}$. En este sentido, no puede entenderse que los valores axiológicos proceden únicamente de elementos fácticos, ya que son esos mismos valores los que identifican y diferencian a las comunidades sociales y por ende, proyectan su influencia en el ámbito educativo.

Esa diferenciación, en muchas ocasiones, nos hace comprobar como expresiones propias del lenguaje ordinario son empleadas para aludir los derechos de los extranjeros, así como los derechos de los inmigrantes. Esto supondría entender también como sinónimos el derecho a la educación de los extranjeros y el derecho a la educación de los inmigrantes. El reconocimiento del carácter universal del derecho a la educación parece en principio reducir la gravedad del problema, en la medida en que se entiende que todos, ya se les considere extranjeros o inmigrantes, tienen idéntico derecho a la educación. Siendo esto cierto, también lo es que la carga de significado real en el lenguaje cotidiano de las dos expresiones resulta diferente.

Es una cuestión de matiz pero que tiene una indiscutible relevancia práctica. La profesora Belloso Martín alude a ello cuando afirma que "conviene partir de una distinción terminológica acerca de la utilización de los términos extranjero o inmigrante. Generalmente cuando se hace referencia a alumnos de origen extranjero se alude a alumnos cuyas familias provienen de otros países y cursan estudios en España. El uso del término inmigrante es más complejo pues no es un dato que deriva necesariamente de la nacionalidad. Se suele considerar alumnos de origen inmigrante a todo los alumnos de origen extranjero salvo los procedentes de los países de la Unión Europea (que cuentan con el estatus de la ciudadanía europea) o de América del norte, es decir, alumnos procedentes de países considerados con origen de inmigración económica cuyas familias llegan a España con la

\footnotetext{
${ }^{10}$ FERNÁNDEZ GARCÍA, Eusebio. "La cultura cívica y los derechos humanos", en Silvina RIBOTTA (editora), Educación en derechos humanos: la asignatura pendiente. Madrid: Dykinson, 2006, p. 48.

${ }^{11}$ SANTANA RAMOS, Emilia. "Los imperativos culturales como garantía de los derechos del inmigrante". Revista de la Facultad de Derecho, núm. 41, 2016, pp. 287-311.
} 
intención de mejorar sus condiciones de vida"12. Este planteamiento pone de manifiesto que, aunque la titularidad del derecho a la educación sea ciertamente universal, común por tanto a los dos colectivos señalados, la realización del derecho subsistencial a la educación del inmigrante llevará consigo una exigencia prestacional para los poderes públicos diferente en cierto modo a la que pudiera llevar la realización del derecho a la educación del extranjero considerada en abstracto.

Habría desde luego, elementos comunes a ambos supuestos. Así, por ejemplo, la necesidad de proporcionar a los extranjeros, cualquiera que sea la razón que les lleva a trasladar su residencia al nuevo país, el nivel del conocimiento adecuado de la lengua en la que se le van a transmitir los contenidos educativos. Pero seguramente no requerirá el extranjero que no traslada su residencia por motivos de necesidad subsistencial o de deseos imperativos de mejora de las condiciones de vida que en su país de origen resultan claramente insatisfactorias que se ponga en marcha un programa concreto de educación intercultural basado en particular en la garantía del reconocimiento cultural, puesto que el extranjero no inmigrante comparte en general los presupuestos culturales comunes a los miembros originarios de la sociedad de acogida.

Y aun, en el supuesto de que no los llegara a compartir plenamente, el carácter estrictamente voluntario de su asentamiento en el país receptor presupone en cierto modo la idea de que por su particular status económico y personal dispone ya de suficientes medios eficaces para no incurrir en la situación de infravaloración y desestimación de sí mismo que normalmente acompaña a la condición del inmigrante que no ve suficientemente reconocidos en el nuevo entorno social a los principios identitarios de la cultura que ha servido de contexto general a la formación de su personalidad y que encuentra serios problemas a la realización de las conductas y actitudes que representan el ejercicio mismo de su derecho a la identidad cultural. La problemática que representa el carácter pluridimensional que se observa en el análisis del derecho a la educación no puede obviar el objetivo declarado que representa el ideal de los derechos humanos frente a la población de acogida. Asi lo defiende Gutmann cuando reconoce que con independencia del carácter subjetivo del derecho a la educación "no puede constituirse en una razón decisiva para prescindir de un análisis de principios de los problemas de la educación" ${ }^{13}$.

Estas apreciaciones obligan a realizar un análisis por separado de lo que pudiéramos denominar el componente lingüístico y el componente cultural de la educación de los inmigrantes. Son cuestiones conectadas pero diferentes, porque como afirma el profesor Ovejero Lucas, "compartir la misma lengua no asegura tener la

\footnotetext{
${ }^{12}$ BELLOSO MARTíN, Nuria. "El derecho a la educación de los extranjeros en una perspectiva multicultural", en Alfonso DE JULIOS-CAMPUZANO (editor), Ciudadanía y derecho en la era de la globalización. Madrid: Dykinson, 2007, p. 289.

${ }^{13}$ GUTMANN, Amy. La educación democrática. Una teoría política de la educación, trad. de Águeda Quiroga. Barcelona: Paidós, 2001, p. 19.
} 
misma cultura" ${ }^{14}$ siempre sobre la base de la filosofía de la democracia cultural aplicada a la educación que conlleva aparejado, no sólo el derecho de los individuos a ser educados en su propia lengua y estilo de aprendizaje, sino también, el derecho a mantener su identidad bicultural, lo cual supone "retener e identificarse con su propia cultura de origen; integrar, de forma constructiva, los valores de la cultura dominante" ${ }^{15}$.

Las garantías que defiende Martínez de Pisón parten de la consideración de universalidad del derecho a la educación y así lo defiende cuando reconoce que el derecho a la educación constituye "un bien universalizable con independencia de la nacionalidad", precisamente por ello, entiende que el concepto todos, debe ser "interpretado en sentido amplio incluyendo a españoles y extranjeros y debe rechazarse cualquier discriminación en la educación por razón de nacimiento, sexo, raza, religión, opinión, etc. tal y como prescribe el artículo 14 de la Constitución" ${ }^{16}$.

Otra cuestión adicional que afecta también de manera significativa a la realización del derecho a la educación de los inmigrantes es precisamente el propio lenguaje de la regulación normalmente establecida para proceder a la aplicación del derecho a la educación, que puede resultar en determinados casos un tanto ofensiva para la propia persona del inmigrante, contribuyendo cuando así sucede a la acentuación de su proceso de baja estima o desvalorización general. Esta situación ocurre, por ejemplo, cuando se utilizan la expresión "alumnos con necesidades educativas especiales", u otras expresiones semejantes, sobre las que se trata de estructurar la educación compensatoria que reclama la necesidad de adaptar el sistema educativo a las particulares condiciones lingüísticas o culturales de los inmigrantes. La profesora Belloso Martín señala en este sentido que "el problema surge cuando no se produce ninguna normativa de desarrollo que haga referencia al apoyo a los niños inmigrantes, por ejemplo, en el caso de la lengua. Como única solución tenemos que remitirnos a los alumnos con necesidades educativas especiales entre los que se acaba incluyendo a los extranjeros, pero distorsionando claramente el concepto de niños con necesidades educativas especiales (los que están en situaciones sociales o culturales desfavorecidas), concepto predicable de los alumnos extranjeros" ${ }^{17}$. Esto situación provoca irremediablemente en los menores un sentimiento de baja autoestima y de no estar a la altura de sus compañeros, a la vez que deriva en la concentración de los menores inmigrantes en determinados centros escolares originando una guetización.

No puede, en este sentido, desconectarse del tema propuesto la idea de que la propia educación compensatoria que se trata de aplicar a la formación de los inmigrantes culturalmente diferentes tiene su origen en la denominada teoría del déficit, implicando de alguna manera la actuación pública encaminada a corregir carencias de tipo cognitivo que en este caso resultarían directamente vinculadas con el origen cultural del

\footnotetext{
${ }^{14}$ OVEJERO LUCAS, Félix. "Como no se debe defender la multiculturalidad”. Letras libres, núm. 13, oct. 2002, p. 32.

${ }^{15}$ AGUADO ODINA, María Teresa. Educación multicultural. Su teoría y su práctica, Madrid: UNED, 2008, p. 51.

${ }^{16}$ MARTÍNEZ DE PISÓN, José. El derecho a la educación y la libertad de enseñanza. Madrid: Dykinson, 2003, p. 138.

${ }^{17}$ BELLOSO MARTÍN, Nuria. Op. cit., pp. 295-296.
} 
inmigrante ${ }^{18}$. Y es que en su versión más comúnmente asumida la compensación "transforma la diferencia en deficiencia y por lo tanto relaciona la diversidad con carencias" ${ }^{19}$.

Otra de las problemáticas que se presenta en la figura de los inmigrantes es precisamente el particular problema que puede llegar a suponer la autoconfesión de la condición irregular por parte del inmigrante cuando éste reclama la realización del derecho a la educación para sí mismo o para los familiares que de él depende. Las dificultades que encuentra el inmigrante para ver reconocido su derecho a instalarse formalmente en la sociedad de acogida, pueden llegar a constituir un serio obstáculo a las posibilidades de realización del derecho a la educación. Así lo defiende la profesora Belloso Martín cuando alude igualmente a esta cuestión al señalar que "esta situación de los menores en centros educativos se complica aún más cuando sus padres o familias se encuentran en una situación irregular. La posibilidad de que la matriculación del hijo en un centro educativo pueda llegar a suponer una ocasión para poner en evidencia la situación de irregularidad de los propios padres puede acabar disuadiendo a las familias de llevarles a ese centro educativo, dejando al menor sin escolarizar" ${ }^{20}$.

Resulta paradójico que el ejercicio del derecho a la educación por parte de los individuos más desfavorecidos en el grupo social puede acabar convirtiéndose en un instrumento de control de su situación por parte de los poderes públicos. Es una situación claramente insatisfactoria que contradice abiertamente el sentido general de la filosofía de los derechos humanos y el objetivo declarado sobre el ideal de la universalidad que se pretende con el derecho a la educación. La solución se presenta en cualquier caso evidente. Habría que eliminar la propia condición irregular de quien pretende ejercitar para sí mismo o para los miembros de su familia el derecho universal a la educación, o por lo menos, mientras ello no sea viable, habría que desconectar la realización de ese mismo derecho a la educación de cualquier posible consecuencia negativa para los intereses de quien lo reclama. En este sentido, la reivindicación del derecho universal a la educación por parte del inmigrante debería suponer un escudo ante la posibilidad de su expulsión del país receptor cuando la información relativa a la situación irregular de la estancia del inmigrante en el mismo se produzca a través de semejante reclamación.

El ejercicio del derecho a la educación debe resultar absolutamente incondicional, sin que pueda ser mediatizado por ninguna circunstancia concerniente a la situación administrativa particular en que se encuentre quien lo reclama para sí mismo o para sus familiares. Así lo expresa claramente Belloso Martín cuando defiende que "todo menor con respecto al cual alguien (sus padres, tutor, guardador de hecho, administración pública) solicite su escolarización gratuita en un nivel de enseñanza obligatoria tiene el derecho fundamental a esa escolarización, sin que eso dependa de la situación jurídica de quien formula dicha solicitud. Esto también significa

\footnotetext{
${ }^{18}$ GARCÍA MARTÍNEZ, Alfonso; ESCARBAJAL FRUTOS, Andrés y ESCARBAJAL DE HARO, Andrés. La interculturalidad. Desafío para la educación. Madrid: Dykinson, 2007, pp. 102-103.

${ }^{19}$ SAGASTIZABAL, María de los Ángeles. "Diversidad cultural y educación”, en María Ángeles SAGASTIZABAL (dirección), Diversidad cultural y fracaso escolar. Educación intercultural: de la teoría a la práctica, Madrid: CEP, 2009, p. 22.
} 
que todo menor en edad de escolarización obligatoria que esté en España en una situación fáctica de residencia tiene necesariamente que estar escolarizado" ${ }^{21}$. Evidentemente la idea de la incondicionalidad del ejercicio del derecho a la educación por parte del inmigrante no debe atender única y exclusivamente al reconocimiento formal de la titularidad del propio derecho, sino también, y de manera muy particular, a las ya aludidas condiciones fácticas de acceso a dicho ejercicio eliminando los obstáculos que puedan presentarse a su realización.

\section{LA DIVERSIDAD LINGÜÍSTICA EN LA REALIZACIÓN DEL DERECHO A LA EDUCACIÓN DE LOS INMIGRANTES}

La capacidad para comunicarse entre los miembros que conforman un grupo social constituye la conditio sine qua non en el proceso de socialización e integración. Precisamente por ello, resulta del todo inimaginable una integración real si se desechara la importancia de la transmisión del lenguaje como medio de comunicación y socialización entre los miembros que conviven dentro de un mismo espacio territorial.

Por todo ello, resulta impensable entender un derecho a la educación eficaz que no tenga en consideración la importancia de la dimensión lingüística que posibilite maximizar las capacidades personales y comunicativas de los educandos.

La incorporación de los inmigrantes a la sociedad de acogida, representa un fenómeno que reclama un esfuerzo común de adaptación por parte de los inmigrantes a la realidad de la sociedad receptora y al mismo tiempo también por parte de los miembros originarios de ésta a la convivencia con otros individuos que puedan tener una lengua comunicacional diferente y que normalmente disponen de presupuestos culturales distintos y en ocasiones contradictorios a los que resultan definitorios de la cultura hegemónica en el país.

El sistema educativo constituye el instrumento idóneo para conseguir dar un cauce real a ese esfuerzo común de adaptación. Lógicamente, si el sistema educativo pretende ser adaptado a los cambios sociales deberá tener muy presente la significativa transformación operada con la llegada masiva en ocasiones de personas que acuden a la tierra prometida intentando alcanzar un mayor nivel de vida y una apertura de posibilidades de desarrollo para ellos mismos y para sus familias que de otro modo no podrían ni tan siquiera pensar.

Los dos elementos citados, la lengua y los presupuestos culturales propios, van a jugar un papel muy distinto, presentando características perfectamente diferenciadas. Los miembros originarios de la sociedad de acogida pueden cerrar de manera irresponsable los ojos ante la gravedad evidente que supone la implantación en la citada sociedad de acogida de individuos con presupuestos culturales nítidamente distintos a los que definen el sentido de la cultura hegemónica. Actuar así es una manera de no querer ver la complejidad del problema. Cabe

\footnotetext{
${ }^{20}$ BELLOSO MARTÍN, Nuria. Op. cit., p. 296.

${ }^{21}$ Ibídem, p. 295.
} 
también que, basándose en la idea de asumir una supuesta superioridad cualitativa de la cultura hegemónica obliguen (directa o indirectamente) los miembros originarios de la sociedad de acogida a los recién llegados a asimilarse en el plano cultural al cuerpo doctrinal de la cultura dominante, dando a entender de forma implícita que ese esfuerzo de asimilación no representa un mayor coste para el inmigrante, el cual además, precisamente por la supuesta superioridad de la cultura dominante, se pretende de manera errónea que ganaría bastante desde el punto de vista de su desarrollo personal con la asimilación cultural que se le fuerza a llevar a cabo.

Es éste, un planteamiento bastante hipócrita de la cuestión, porque los miembros originarios de la sociedad de acogida no estarín seguramente dispuestos a llevar a cabo el esfuerzo que reclaman por parte de los inmigrantes. El coste moral y psicológico que supone hacer dejación de los presupuestos fundamentales de la cultura identitaria de cada individuo es evidente, y por lo demás es un coste que resulta común tanto a los inmigrantes como a los miembros originarios de la sociedad de acogida. Pero, tratándose de un coste de carácter moral y psicológico le puede resultar relativamente cómodo al diseñador de las políticas educativas ocultar su sentido real, sobre todo teniendo en cuenta que va a ser la propia cultura dominante la que va a proporcionar la interpretación oficial acerca de lo que representa ese coste.

El diseñador de las políticas educativas puede poner en marcha estrategias de ocultamiento del sentido real que supone el sesgo cultural que vaya a asumir la política educativa de que se trate. Pero donde no valen esas estrategias de ocultamiento es cuando nos situamos en el plano de la diferencia lingüística. Aquí la diferencia salta a la vista, y el esfuerzo que conllevaría el aprendizaje de la lengua común tanto a los inmigrantes como a los miembros originarios de la sociedad de acogida también.

Podemos hacer como si no existieran diferencias culturales significativas entre unos y otros habitantes de un territorio común y podemos también hacer como si la asimilación de los individuos a los presupuestos definitorios de la cultura hegemónica fuera una cuestión de mera voluntad, que costará muy poco llevar a efecto. Pero no podemos cerrar los ojos ante la evidencia que significa encontrarnos con un individuo que no puede entrar en contacto con los demás porque sencillamente no les entiende, al usar una lengua distinta a la que o les es común a todos ellos. Si queremos que los inmigrantes se integren a la sociedad de acogida, esa integración pasa lógicamente por resolver el problema de la incomunicación que genera el uso de lenguas distintas que no resultan conocidos por todos los habitantes del mismo territorio.

Lo ideal en este tipo de supuestos sería que el sistema educativo ofreciera al inmigrante la posibilidad de acceder al conocimiento de la lengua oficial de la sociedad de acogida a través de la correspondiente acción formativa, dejando en cualquier caso en manos del inmigrante la posibilidad de comunicarse en una u otra lengua. Esta es la tesis más coherente con lo que antes indicábamos con respecto a la necesidad de plantearnos el problema de la realización de los derechos sociales como un problema de realización de derechos en clave de 
identidad cultural.

Es además la tesis que atiende a grandes rasgos la consideración de la dimensión lingüística de las culturas y a los imperativos que al respecto impone la idea misma de la diversidad cultural. La opinión de Kymlicka es determinante a este respecto "es difícil que los idiomas sobrevivan en sociedades industrializadas modernas si no se utilizan en la vida pública. Dada la difusión de la educación regularizada las elevadas exigencias culturales en el trabajo y la extensa interacción con los órganos del gobierno, cualquier idioma que no sea un idioma público pasa a quedar tan marginalizado que es probable que sólo sobreviva entre una pequeña élite o de una forma ritualizada, o en zonas rurales aisladas, no como un idioma vivo o en desarrollo, base de una cultura social floreciente. Las decisiones del Estado sobre el idioma de los servicios públicos y la enseñanza pública, son de hecho decisiones sobre qué culturas sociales podrán existir dentro del país"22.

La puesta en práctica de ese modelo ideal conforme al cual el inmigrante tiene acceso al conocimiento de la lengua oficial de la comunidad de acogida, pero sin embargo no se ve obligado a utilizarla en sus relaciones sociales porque los propios miembros originarios de la sociedad de acogida llevarían a cabo el esfuerzo necesario para llegar a comprender el mensaje, queda sin embargo muy lejos de la realidad. Se pagaría un precio muy alto tanto en el plano económico, con la consiguiente necesidad de acudir permanentemente a equipos específicos de traducción, como en el plano de la inmediatez de la comunicación.

El inmigrante con una lengua distinta a la lengua comúnmente utilizada en el territorio en el que reside no puede pretender que todos aquellos que van a convivir con él se adapten a las exigencias comunicativas que impone el uso exclusivo de esa misma lengua. Lo que sí parece claro es que se le han de facilitar todos los medios para poder llegar a comunicarse de manera fluida en la lengua oficial de la comunidad receptora. La realización de esa posibilidad es algo que proporcionará beneficios inmediatos al inmigrante, que se integrará de manera más fácil en el grupo social, pero también indirectamente a la sociedad de acogida, que se verá enriquecida con la aportación comunicativa de un nuevo miembro, amén del provecho que se pueda obtener por el hecho de que muy probablemente los resultados laborales del recién llegado se verán incrementados de manera notoria por esa misma facilidad en el ámbito comunicacional que proporciona el conocimiento de la lengua comúnmente usada por los miembros originarios de la sociedad de acogida.

Por lo demás, si bien parece razonable no exigir de los miembros originarios de la sociedad de acogida ni el esfuerzo que conlleva el aprendizaje de la lengua de cada uno de los inmigrantes ni el peaje económico que supondría el establecimiento de todo un sistema institucional de traducción de las más diversas lenguas, resultaría conveniente que se pusiera sin embargo a disposición de los propios miembros originarios de la sociedad de

\footnotetext{
${ }^{22}$ KYMLICKA, Will. "Nacionalismo minoritario dentro de las democracias liberales", en Soledad GARCÍA y Steven LUKES (comps.), Ciudadanía: justicia social, identidad y participación. Madrid: Siglo XXI, 1999, p. 133.
} 
acogida la posibilidad de acceder si así lo desean al conocimiento de esas mismas lenguas.

Sería una forma de facilitar la comunicación por su parte con los recién llegados a la sociedad receptora, pero también de promover un cierto reconocimiento social de la identidad del propio inmigrante. Y es que ésta presenta en muchas ocasiones, junto a la faceta estrictamente cultural, también la faceta lingüística que le distingue nítidamente de las condiciones identitarias de los miembros originarios de la sociedad de acogida. Eso además de que también puede considerarse a la lengua propia como uno de los elementos que definen típicamente la identidad cultural en sentido amplio del individuo de que se trate.

La estructuración de un sistema educativo que propicie una posibilidad real para los miembros del grupo social de conocer las distintas lenguas identitarias coincidentes en él cumpliría a este respecto una función indiscutiblemente positiva, tanto en el plano estrictamente comunicacional como en el del reconocimiento cultural en sentido amplio.

Un problema real se plantea cuando el inmigrante rechaza las posibilidades que le ofrece el sistema educativo en relación al aprendizaje del instrumento oficial de comunicación en la sociedad receptora. Para este caso regiría la lógica de la enseñanza obligatoria. Está claro que el inmigrante se va a ver notablemente obstaculizado en lo que concierne a la realización de un plan de vida libremente concebido por él mismo si se encuentra incapacitado para comunicarse con los demás miembros del grupo social en cuyo entorno ha de discurrir su existencia. Una actitud de rechazo absoluto al aprendizaje de esta lengua común podría llegar a denotar una cierta incompetencia del individuo para operar con pleno protagonismo en la realización de sus actos y en la toma de decisiones relevantes, porque sería algo así como renunciar a la posesión de un instrumento que desde luego resulta de gran utilidad para desarrollarse de una manera más plena en la comunidad social de acogida.

Otra cosa muy distinta es que se le obligue al inmigrante a distanciarse de su propia lengua prohibiéndole su utilización. Sería ésta una solución aberrante, precisamente porque, como ya hemos dicho, la lengua propia tiene también una indiscutible connotación cultural. En este sentido, la prohibición del uso de la lengua propia en la sociedad de acogida equivaldría en cierto modo, a la prohibición irresponsable de la realización de conductas que proyectan los principios definitorios de la cultura identitaria del sujeto. El mantenimiento general de la posibilidad de expresarse cada individuo con su lengua propia constituye un ejercicio concreto del derecho a la identidad cultural que a todos nos corresponde, por tratarse precisamente de un derecho de carácter universal.

El ejercicio del derecho a la identidad cultural que presupone el uso de la lengua propia debería también cubrir al inmigrante con lengua propia diferente a la del país de acogida ante los juicios erróneos acerca de su aptitud académica general que suelen muchas veces asociarse con ella. Tal y como se viene defendiendo en este trabajo, "determinados problemas que suelen vincularse a diferencias de tipo lingüístico o de carácter étnico en el 
caso de ciertas minorías como sucede, por ejemplo, con determinados tipos de habla dialectales o cuando se producen situaciones escolares de deficiente rendimiento en legua, son interpretados como signos de baja habilidad para las cuestiones académicas. En ciertos casos, algunas de estas falsas interpretaciones sobre las capacidades de los alumnos son el origen de etiquetas que en modo alguno son ciertas y que nada le benefician" ${ }^{23}$. $\mathrm{Al}$ contrario, el esfuerzo adicional que para el inmigrante con lengua propia supone comunicarse con mayor o menor éxito en el ámbito educativo es una prueba de merito y capacidad por su parte que debería en cualquier caso ser tenida en cuenta.

El sistema educativo deberá proporcionar al inmigrante los medios necesarios para acceder al conocimiento más preciso de la lengua oficial o de las lenguas de uso más extendido en la comunidad social de acogida. Deberá también si ello fuera posible poner a disposición de los miembros originarios de la sociedad de acogida instrumentos formativos que les permitan también acceder al conocimiento de las lenguas maternas o naturales de los recién llegados. Pero deberá igualmente esforzarse porque tanto dentro como fuera del ámbito escolar, se sienta el inmigrante suficientemente cómodo al no verse privado de la posibilidad real de expresarse en su vida cotidiana en la lengua que de alguna manera define a su propio ser identitario.

Por lo demás, la puesta a disposición de los cohabitantes en un mismo territorio, tanto de los inmigrantes como de los miembros originarios de la sociedad de acogida, del acceso al conocimiento de otras lenguas diferentes que puedan no resultar compartidas ni por unos ni por otros, contribuirá seguramente a propiciar una mayor apertura cultural por parte de todos. Y es que el conocimiento de las distintas lenguas constituye también en parte un conocimiento de las culturas identitarias con las que esas mismas lenguas guardan una mayor relación.

La disposición para el aprendizaje de los idiomas representa, en este sentido, también una disposición favorable al contacto con lo que en principio nos puede resultar lejano y diferente. Una sociedad en la que todos los individuos compartan esa misma disposición será muy probablemente una sociedad en la que ninguno de sus miembros se sentirá culturalmente desplazado. La estructuración del sistema educativo en lo que al aprendizaje de los idiomas respecta tendría que tener muy en cuenta ese dato concreto y no fijarse exclusivamente en el hecho, por otra parte, igualmente evidente, de que el conocimiento de los idiomas contribuye también en muy amplia medida a favorecer el progreso profesional de quien de él dispone.

\section{EL RECONOCIMIENTO DE LA DIVERSIDAD CULTURAL EN EL AMBITO EDUCATIVO}

La dimensión cultural en el ámbito educativo en general, y muy en particular en la figura del inmigrante constituye "la mejor garantía del respeto a los derechos humanos, la implantación de una cultura y educación de

${ }^{23}$ GARCÍA MARTÍNEZ, Alfonso; ESCARBAJAL FRUTOS, Andrés y ESCARBAJAL DE HARO, Andrés. Op. cit., p. 105. vol.11, nº. 01, Rio de Janeiro, 2018.pp. 383-407 
esos derechos. Los derechos por muy consagrados que estén en las Constituciones se respetan cuando son conocidos y ejercitados, previas la correspondiente formación y asunción del valor que representan. Los valores que implican estos derechos sólo se alumbran y adquieren sentido cuando se asumen activamente y se practican en la propia vivencia personal" ${ }^{24}$. Se defiende, por tanto, que un proyecto educativo que tenga en sus planes de estudios las garantías exigibles a todas las personas sin discriminación cultural, garantiza un mejor desarrollo en el avance del reconocimiento de los derechos de los inmigrantes.

Entre los objetivos de las políticas educativas, debemos destacar el dato de que trata de evitar la circunstancia de que la cultura adquirida sea una realidad que aísle y condicione a sus miembros, restringiendo en último término el uso de su libertad, en la medida en que los individuos se ven constreñidos en determinados casos por los propios dirigentes del grupo cultural a permanecer anclados en los principios definitorios de su propia cultura. Esta circunstancia es propia de las sociedades cerradas donde los elementos culturales ajenos a los presupuestos típicos de la cultura primaria de dicha sociedad son normalmente desterrados y expulsados sin mayores miramientos.

La idea de cultura que deberá transmitirse dentro de los programas educativos debe lógicamente rechazar tanto la cerrazón cultural entendida como las actitudes de desprecio y de exclusión de las culturas diferentes a la cultura hegemónica como la cerrazón de las culturas que no posibilitan de hecho a sus miembros a apartarse del credo cultural que se les ha venido inculcando desde los primeros años de su niñez. La apertura cultural deberá vincular tanto a quienes comparten los presupuestos de la cultura hegemónica como a quienes se adscriben explícita o implícitamente a las culturas minoritarias.

Habría, en este sentido, que desconfiar especialmente de quien dispone del poder real para eliminar o por lo menos para obstaculizar la acción de esa pretendida apertura cultural que en el caso de la cultura dominante serán los miembros de la sociedad de acogida en general, y en el caso de las minorías culturales, de manera más específica, de los líderes carismáticos con capacidad de influencia suficiente como para convencer a quienes comparten sus propios presupuestos culturales de las supuestas desventajas que para ellos mismos representaría paradójicamente el conocimiento y el mero hecho de entrar de alguna manera en contacto con otras culturas identitarias diferentes a la suya.

La educación cumple una función social importante, entre otras cosas porque constituye un derecho imprescindible para la integración del individuo dentro de su sociedad. La educación permite a todos los sujetos, en mayor o en menor medida, la posibilidad de formarse en aquellos valores que permiten una mejor integración dentro de la sociedad en la que habitan. No cabe duda de que esta integración social presupone, por un lado, la posibilidad que tiene el individuo de proceder a integrarse en conformidad con los presupuestos de la cultura

\footnotetext{
${ }^{24}$ LÓPEZ- BARAJAS, Emilio y RUIZ CORBELLA, Marta. Derechos humanos y educación. Madrid: UNED, 2000, p. 40.
} 
propia en la que ha desarrollado su existencia y, por otro lado, el fundamento universal que permite asimilar el valor del respeto y la tolerancia en clave de identidad cultural con la exigencia inescindible del valor que comprende el reconocimiento del carácter universal de los derechos humanos. Por ello resulta incuestionable el beneficio que genera en su perspectiva social la educación al facilitar la participación activa del individuo en la vida social.

El profesor García Hoz reconoce que la educación vendrá a ser entendida como "el perfeccionamiento intencional de las facultades específicas del hombre"25. Con esta afirmación viene a poner de manifiesto que las capacidades y facultades que tiene el sujeto por su propia naturaleza son potenciadas a través del proceso educativo. No cabe duda que la educación permite formar en el individuo su propia personalidad atendiendo a estímulos e información de la realidad que le rodea. En este sentido, los valores, la cultura, la religión, la lengua y las tradiciones serán determinantes en el comportamiento del sujeto cuando se relaciona en un determinado entorno social. Es por ello que no se puede obviar la importancia que tiene la educación en el desarrollo de la personalidad del individuo.

La educación tiene un proceso crucial que va determinado en relación con el transcurso del tiempo. Podría decirse, sin duda alguna, que el resultado que ofrece el ejercicio del derecho a la educación es gradual. Los modelos educativos en los que se ve sujeto el individuo desde su proceso de aprendizaje a su proceso de asimilación de conductas constituyen la base de la educación. Se parte de la base de que el individuo debe de manera natural visionarse como un hombre libre y no como un ser devaluado y es precisamente esa misma libertad la que le debe permitir reconocer cuáles son los modelos o valores que le rodean y discernir de manera racional y autónoma sobre lo que le conviene para alcanzar su libre desarrollo personal.

En el proceso educativo destacamos la importancia que desempeña la neutralidad dentro de las sociedades multiculturales donde encontramos la existencia de una diversidad cultural. Ya que, como hemos comprobado, la educación no deja de ser más que una relación de respeto entre todos los individuos que conforman la comunidad social.

La lógica del presupuesto de la educación partiría primitivamente del entorno más próximo al sujeto que vendría a ser el núcleo familiar. Una prueba de ello la encontramos en el vigente Código Civil español cuando en el artículo 1094 sitúa al modelo que representa el padre de familia como el comportamiento que tiene que exigirse en la realización de la obligación de conservar la cosa que tiene que ser entregada para dar cumplimiento a una obligación jurídica de dar. Otra muestra de ello la vemos en la Ley Fundamental de Bonn, donde se reconoce que "el cuidado y la educación de los hijos son el derecho natural de los padres y deber que les incumbe prioritariamente a ellos". Queda patente igualmente en el enunciado del artículo 39.2 de la Constitución española

\footnotetext{
${ }^{25}$ GARCÍA HOZ, Víctor. Diccionario de pedagogía. Barcelona: Labor, 1974, p. 292.
} 
al afirmar que "Los poderes públicos aseguran, asimismo, la protección integral de los hijos, iguales estos ante la Ley con independencia de su filiación y de la madre, cualquiera que sea su estado civil". A este respecto Martínez López-Muñiz defiende que "la educación supone respetar el derecho-deber de los padres"26.

En el preámbulo de la Ley Orgánica 2/2006 de Educación, se resalta que "la educación es el medio más adecuado para construir su personalidad, desarrollar al máximo sus capacidades, conformar su propia identidad personal y configurar su comprensión de la realidad, integrando la dimensión cognoscitiva, la afectiva y la axiológica". Será por consiguiente el Estado quien debe garantizar el fundamento del deber que ostenta el valor de la educación como un auténtico derecho integrador.

La educación supone un proceso imprescindible para la integración que se debe proyectar con carácter general a todos los sujetos de cualquier país, y en particular a los individuos que conforman la población inmigrante. También se debe garantizar y hacer posible que el individuo reciba una formación no sólo estrictamente académica sino más precisamente una educación que también permita abarcar otro tipo de facetas diferentes tanto personales como culturales ${ }^{27}$. En consecuencia, la educación que vaya a recibir depende en primera instancia la realización del objetivo de garantías el pleno desarrollo de la personalidad del individuo.

No faltan sin embargo autores que inciden en la necesidad de reconocer que el objetivo de la educación va más lejos de lo que representa la simple posibilidad de la autodeterminación individual que supone el libre desarrollo de la personalidad. Es el caso del profesor Nuevo López, que señala que "la finalidad constitucional de la educación no se limita a la promoción de la libertad entendida como mera autodeterminación individual. Más allá del fomento del espíritu crítico para hacer posible la autodeterminación individual, es necesario que el educando reciba alguna orientación, por mínima que quiera considerarse, sobre como ejercer de manera responsable su libertad. El espíritu crítico debe versar sobre algo, pues de lo contrario la libertad, concebida como indeterminación, carecería de objeto sobre el que posarse, y no podría orientar la acción (libre) del educando"28.

El requerimiento de una educación que incida en la idea de la responsabilidad en el ejercicio de la libertad no contradice, en cualquier caso, la apuntada coincidencia entre los conceptos de libre desarrollo de la

\footnotetext{
${ }^{26}$ MARTÍNEZ LÓPEZ-MUÑÍZ, José Luis. Op. cit., p.245.

${ }^{27}$ PAREKH, Bhikhu. Repensando el multiculturalismo. Barcelona: Istmo, 2005, p. 337, señala a este respecto que "una buena educación debería exponer a los estudiantes a distintas concepciones de la vida buena, de sistemas o formas distintos de conceptualizar experiencias familiares y ayudarles a captar el espíritu de otras culturas. Debería enseñarles a ver el mundo a través de sus ojos y a apreciar su fuerza y sus limitaciones. A la vez que se desarrolla la capacidad de pensamiento independiente, de análisis, de crítica, etc., deberían cultivarse también capacidades más "suaves" y menos agresivas como la imaginación empática, la habilidad para meterse en la piel de los demás y sentir con y para ellos, la voluntad de verse a sí mismo a través de los ojos de los otros, la capacidad de escucharles con sensibilidad y simpatía. Los estudiantes son miembros de sus propias comunidades étnicas y culturales, ciudadanos de sus comunidades políticas y, también, seres humanos. Un buen sistema educativo debe atender a estas tres vertientes. Debería ayudar a los alumnos a entender la historia, la estructura social, la cultura, las lenguas, etc. de su propia comunidad política y cultural para permitirles entenderse a sí mismos mejor y encontrar su camino en el seno de estas comunidades".
} 
personalidad y pleno desarrollo de la personalidad puesto que el propio ejercicio de la autodeterminación individual se produce en un contexto necesariamente social en el que el sujeto se ve obligado también a respetar el libre desarrollo de la personalidad de los demás. La apelación al uso responsable de la libertad es una exigencia de la vida en sociedad que no puede dejar de tener en cuenta el sistema educativo de cualquier comunidad.

Uno de los objetivos que desempeña la educación es que constituye un elemento básico de la integración social que permite, sin lugar a dudas, superar las posibles barreras o dificultades de distinto tipo que tantas veces se encuentra el inmigrante en su intento de integración en el país de acogida. Esta integración social conllevaría implícitamente la asunción del principio educacional que responde en buena medida a la idea de alcanzar una convivencia social pacífica, que es, en definitiva, la máxima que desea cualquier Estado. Son muchas las instituciones y organismos que se han preocupado por atender la consideración sobre la relevancia que tiene la educación como valor fundante del sistema social. Una prueba de ello la tenemos en el reconocimiento realizado por la Declaración de los Principios de Cooperación Cultural Internacional, de 4 de noviembre de 1966, cuando reconoce en su artículo primero que "Toda cultura tiene una dignidad y un valor que deben ser respetados y protegidos".

Ante la lógica que plantea el principio de no discriminación, la educación en la multiculturalidad que habrían de recibir tanto los inmigrantes como los miembros originarios de la sociedad de acogida constituye en sí mismo un avance considerable en el posibilitamiento de la realización del libre desarrollo de la personalidad del inmigrante. Es precisamente por ello que hay que considerar la insoslayable necesidad de una educación que se proyecte de manera inmediata sobre el sentido de la dignidad del ser humano, así como el fortalecimiento de su libre desarrollo de la personalidad atendiendo al valor del aprendizaje desde los pilares educativos que representan el respeto, la tolerancia y sobre todo el reconocimiento de los derechos fundamentales.

El sentido de la educación como un derecho social supone apostar no solamente por un modelo académico que se proyecte sobre la base que permitirá al sujeto una construcción de su vida basada en el propósito de alcanzar unas determinadas cotas de bienestar, sino que además deberá procurar el establecimiento de modelos de conducta encaminados a propiciar en la mayor medida posible una vida social que pueda merecer con toda propiedad la calificación de vida social justa.

No cabe duda de que las mutaciones sociales hacen que las sociedades se proyecten con un carácter interconectado que acompaña necesariamente la multiculturalidad. En este sentido, es precisamente donde la educación debe proyectar su dimensión especialmente significativa. Sin duda alguna supone un reto para las culturas societales concretamente lo que afecta de manera más directa a los sectores devaluados como puede ser el

\footnotetext{
${ }^{28}$ NUEVO LÓPEZ, Pablo. La Constitución educativa del pluralismo. Una aproximación desde la teoría de los derechos fundamentales. La Coruña: Netbiblo, 2009, pág.56.
} 
caso de los sujetos inmigrantes, ya que su integración no podrá en muchas ocasiones darse de manera natural.

Los sectores menos favorecidos de la comunidad social deberán estar contemplados como un fundamento de primer orden en la puesta en marcha de las políticas educativas para hacer valer su dignidad en el país de acogida. Esas políticas de educación deberán ir encaminadas a la formación educacional de los individuos con un marcado elemento de toma en consideración de la diversidad cultural, reconociendo en la misma diversidad un factor importante de riqueza cultural, así como un factor propiciador de progreso que permitirá a los sujetos originarios del país de acogida conocer los contenidos definitorios de otras culturas identitarias que hasta el momento desconocían, basándose en la aplicación de los valores de respeto mutuo, tolerancia y reconocimiento en la diversidad cultural, dejando abierta la puerta a la efectiva consecución de una sociedad basada en la igualdad y no discriminación de las personas.

El derecho a la educación se consolida como uno de los derechos humanos más relevantes porque ayuda a la persona a tomar por sí misma decisiones cruciales para su realización personal. A través de los conocimientos recibidos podrá discernir efectivamente entre las diferentes opciones que se le presentan para decantarse por la que entienda que resulta más correcta y la que le produzca un mayor interés personal para la realización de su proyecto vital. Gracias a la educación recibida el individuo tendrá implícita una libertad para optar y elegir lo más adecuado para configurar el pleno desarrollo de su propia personalidad.

En definitiva, la formación que proporciona la estructuración del modelo de educación configurado sobre los pilares de la libertad permite alcanzar al sujeto una mejor y mayor integración en la comunidad social en donde se encuentra residiendo.

Los derechos sociales en general, y especialmente el derecho a la educación, servirán para que los inmigrantes den un paso hacia adelante para lograr la debida realización de una de sus metas principales como lo es el reconocimiento y la equiparación en igualdad de condiciones con los derechos que ostentan los miembros de la sociedad receptora.

El papel de la educación de cara a la integración de los inmigrantes tiene una doble dimensión, por un lado, enseña a los nacionales desde la perspectiva de los valores en que están fundamentados los derechos humanos a respetar a los no nacionales que residen en el mismo ámbito territorial y por otro, transmitirá a los no nacionales cuáles son los valores nacionales que han de compartirse por resultar los valores que orientan el principio de universalidad de los derechos humanos. La formación en valores funciona así como "un instrumento para lograr la integración de los sujetos procedentes de distintos referentes culturales, al objeto de lograr una formación ciudadana en el contexto de un Estado democrático" ${ }^{29}$. Estaríamos reconociendo a la diversidad como

\footnotetext{
${ }^{29}$ PÉREZ SOLA, Nicolás. "Nuevos retos en el ejercicio de los derechos educativos: la incorporación del alumno inmigrante al sistema educativo y la educación en valores”, en José Luis CASCAJO CASTRO, Manuel TEROL BECERRA, Antonio
} 
un dato de hecho que condiciona inexcusablemente a la estructuración del sistema educativo. En este sentido, habría que decir que "educar para la diversidad cultural supone una actitud de valoración positiva hacia la comunicación e interacción entre culturas y hacia la comprensión de lo diverso como un factor de aprendizaje positivo y necesario en las actuales instituciones educativas... Aprovechar educativamente la diversidad cultural pasa por reconocer que lo común es la diversidad y la diversidad debe ser desde la perspectiva pedagógica lo común en los diseños y propuestas de intervención educativa que se considere ya no sólo oportunos y adecuados sino imprescindibles en una sociedad democrática" ${ }^{30}$.

La plena integración de la persona dentro de una determinada comunidad social deberá realizarse de forma que la aceptación por parte del individuo de los valores comunes no lleve implícita la renuncia a sus señas de identidad individuales o a las del grupo cultural al que pertenece, o en el caso de que tuviera que renunciar a determinados valores, se sacrificarían aquellos que ocasionen un daño relevante a terceros o colisionen y que sean abiertamente incompatibles con los valores de la sociedad donde el sujeto desarrolle su existencia por asumir estos últimos un significado coherente con la imperativa aplicación del principio de universalidad de los derechos humanos. Fuera de este supuesto, cualquier vulneración que experimente la identidad originaria de la persona, que no sea voluntariamente deseada, se traduce en una agresión del derecho fundamental de la libertad de conciencia $^{31}$, y por extensión al derecho al pleno desarrollo de la personalidad del individuo.

El hecho que la señalada integración deba realizarse en un contexto de convivencia entre culturas diferentes nos obliga a hacer algunas consideraciones sobre el significado del pluralismo en el ámbito educativo, para discernir después cuál es la mejor opción educativa posible entre las que se pueden aplicar en el propio contexto de la diversidad cultural.

\section{EL PLURALISMO COMO VALOR ESENCIAL EN EL PROCESO EDUCATIVO EN LAS SOCIEDADES DEMOCRÁTICAS}

El pluralismo es uno de los valores supremos que se encuentra reconocido en la Constitución española, constituyéndose como uno de los pilares esenciales de nuestra sociedad democrática ${ }^{32}$. Aunque existen autores

DOMÍNGUEZ VILA, Vicente NAVARRO MARCHANTE (coordinadores), Derechos sociales y principios rectores. Valencia: Tirant lo Blanch, 2012, p. 366.

${ }^{30}$ LEIVA OLIVENCIA, Juan José. Convivencia y educación intercultural: Análisis y propuestas pedagógicas. Alicante: ECU, 2011, p. 13.

${ }^{31}$ LLAMAZARES FERNÁNDEZ, Dionisio. Educación para la ciudadanía democrática y objeción de conciencia. Madrid: Dykinson, 2009, pp. 59-60.

32 En el artículo primero de la Constitución española se hace referencia expresa al valor supremo "pluralismo político". Pero en el ámbito político no termina su concepción como valor superior del ordenamiento jurídico, el pluralismo se halla conectado con otros dos conceptos que determinan su contenido: por una parte, con el pluralismo sin calificativos, como manifestación de un sistema social no uniforme al que se ha de aplicar un ordenamiento jurídico que se pretende respetar las diferencias existentes entre sus destinatarios, y por otra parte, con la libertad, desde el momento en que ese pluralismo está calificado como "político" y por 
que no defienden el pluralismo como el valor que fundamenta el reconocimiento de los derechos, sino como una "situación estructural de una sociedad en la que se respetan los derechos" ${ }^{33}$. Lo cierto es que la conexión entre el pluralismo y la realización de los derechos resulta más que evidente en el caso que nos ocupa ${ }^{34}$.

Una sociedad pluralista ${ }^{35}$ es entendida como aquella sociedad que debe garantizar el respeto en el ejercicio de los derechos de cada individuo por parte de las demás personas. Es por ello por lo que la enseñanza deberá ser tan pluralista como lo es, al menos, la sociedad dentro de la cual se desarrolla el modelo educativo de que se trate para que encuentren en ella un adecuado acomodo las diferentes culturas y estilos de vida de los individuos que integran efectivamente el grupo social. La negación de este valor supondría un atentado directo contra todo Estado democrático convirtiéndose en una sociedad sin ninguna clase de libertades ni acomodo para la defensa de los derechos de sus miembros. La proclamación de las libertades y de los derechos fundamentales que llevan a cabo los textos constitucionales tendría en tal caso un carácter puramente nominal, distorsionándose en consecuencia su significado emancipatorio.

El profesor Ara Pinilla defiende la idea de que el diseño de los contenidos docentes se ha hecho sensible a "la necesidad de incorporar información acerca de los procesos democráticos y del contenido de la participación como instrumento de emancipación individual. El concepto de ciudadanía ha cobrado aquí relevancia en su doble acepción de titularidad de los derechos y de criterio de pertenencia del individuo a una concreta comunidad. Su vinculación con los derechos y deberes justificaría sobradamente la consideración de la educación para la ciudadanía junto a (directamente implicada con) la educación en y para los derechos humanos"36. A tal respecto, resulta del todo destacable el valor que asume la educación en la Declaración Mundial de Educación para Todos, cuando reconoce que "la educación es un derecho fundamental para todas las personas, mujeres, hombres, de todas las edades y en todo el mundo. Cada persona, niño, niña, joven y adulto debe beneficiarse de las oportunidades educacionales diseñadas para satisfacer sus necesidades básico, desarrollar sus plenas capacidades,

tanto se pretende que sea operativo en el campo de las relaciones sociales organizadas políticamente, siendo éste precisamente el campo en el que opera la libertad.

${ }^{33}$ SERNA BERMÚDEZ, Pedro. "La dignidad de la persona como principio del derecho público". Derechos y Libertades, núm. 4, 1995, p.293.

${ }^{34}$ Esta conexión con el pluralismo político con otros pluralismos ha llevado al TC a confundir en alguna de sus resoluciones la formulación que expresamente aparece en el art. 1.1 CE con otros conceptos en principio ajenos al mismo. A modo de ejemplo, podemos citar la STC 5/1981, de 13 de febrero, en la que el Tribunal Constitucional se refiere al pluralismo educativo y lo considera contenido en el art. 1.1CE.

${ }^{35}$ ANDER-EGG, Ezequiel. Diccionario de educación. Córdoba, AR: Editorial Brujas, 2014, p. 186, establece que el término pluralismo se aplica a "diferentes tipos de realidades; así, puede hablarse de pluralismo en lo filosófico, sociológico, ideológico, religioso, cultural y en las ideas políticas. Como actitud vital, el pluralismo significa aceptar la pluralidad de tendencias y aspectos diferenciales que se dan en el mundo moderno, en todos los ámbitos de la realidad humana. Implica aceptar la coexistencia de religiones, ideologías, filosofías, culturas, ideas y el derecho a la libre expresión de las mismas. Si además se acepta que los otros pueden tener parte de razón o una posición más aceptable o verdadera, esto supone una disposición de ánimo pronta a oír y subordinar el propio punto de vista a las perspectivas o puntos de vista de los demás".

${ }^{36}$ ARA PINILLA, Ignacio. La difuminación institucional del objetivo del derecho a la educación. Madrid: Dykinson, 2014, p.174. 
vivir y trabajar en dignidad, mejorar la calidad de sus vidas y tomar decisiones".

Dentro del contenido del derecho fundamental a la educación que reconoce el modelo constitucional español, resulta destacable el marcado carácter pluralista que garantiza el contenido normativo. Se puede, en este sentido, citar los ejemplos que proporcionan la libertad de enseñanza que protege a la educación de las posibles influencias monopolísticas, sobretodo en esos aspectos que son susceptibles de manipulación en los ámbitos ideológicos, intelectuales y políticos, el derecho de los padres de elegir centro y formación religiosa y moral para sus hijos, la libertad de cátedra, el derecho a la participación en el control y gestión de los centros sostenidos con fondos públicos, el derecho a crear y dirigir centros docentes, etc.. ${ }^{37}$.

Entre los derechos que proclama y protege el modelo constitucional de 1978, se encuentra la libertad ideológica que deberá ser entendida en el contexto que asume el respeto de los derechos individuales de los demás. Ello conlleva que los Estados democráticos, muy lejos de querer adoctrinar (política, filosófica y/o moralmente) a sus ciudadanos, deban constituirse como entidades preocupadas por alcanzar la mejor resolución de los conflictos que entre los miembros de las diferentes culturas e ideologías se puedan llegar a plantear dentro de una sociedad.

Según el profesor Souto Paz, el pluralismo ideológico que se debe implantar en los centros escolares debe ser radicalmente opuesto al adoctrinamiento ideológico. Se debe en consecuencia facilitar la creación de escuelas plurales desde el punto de vista ideológico donde los estudiantes reciban una educación no adulterada en un proceso de formación activo por parte de la comunidad estudiantil huyendo de todo sistema donde el alumno resulte ser un mero receptor acrítico y ciego de doctrinas ideológicas decididamente inflexibles. Esto es tanto más difícil cuando se constata que "en general los patrones educativos tienden a la homogeneización" 38 .

Tanto en las escuelas públicas como en los colegios privados sus idearios y la libertad de enseñanza de su profesorado deberán respetar (por encima de lo que le puedan dictar sus propias convicciones personales) la libertad y la dignidad del alumnado para favorecer "el pleno desarrollo de la personalidad humana, en el respeto a los principios democráticos de convivencia y a los derechos y libertades fundamentales de la persona" ${ }^{39}$. Este debería ser el resultado final de ese ideario universal que tendrían que perseguir las diferentes ofertas educativas como asílo establece, por lo demás, el tenor literal del artículo 27.2 de la Constitución española ${ }^{40}$.

El contenido que se desprende del Constitucional español viene entendido como un límite concreto al pluralismo ideológico en materia educativa y por extensión al neutralismo absoluto. A modo de ejemplo, sería

\footnotetext{
${ }^{37}$ ROJAS RIVERO, Gloria Pilar. "El derecho a la educación", en José Luis MONEREO PÉREZ (director) y Luis Ángel TRIGUERO MARTÍNEZ (coordinador), Los derechos de los extranjeros en España. Estudio de la Ley Orgánica 2/2009, de 11 de diciembre, de reforma de la Ley Orgánica 4/2000. Madrid: La Ley, 2010, p. 258.

${ }^{38}$ ESCARBAJAL, A., Interculturalidad, Mediación y trabajo colaborativo, Narcea, Madrid, 2010, p. 43.

${ }^{39}$ SOUTO PAZ, José Antonio. "El derecho a la educación”. Boletín de la Facultad de Derecho de la UNED, núm. 1, 1992, p. 38.
} 
contraria al pluralismo ideológico y a los valores y principios constitucionales aquella enseñanza que defienda el racismo, la xenofobia o que sea reacia a la instauración de un régimen jurídico que posibilite la realización de una efectiva igualdad de género. Este límite constitucional, como ya hemos indicado, será aplicable tanto en la enseñanza pública como en la privada ${ }^{41}$.

Precisamente por ello, el pluralismo ideológico dentro de los procesos educativos debe centrarse en transmitir al alumno toda una serie de valores de los que, si bien puede decirse que no necesariamente se encuentran por encima de todas las ideologías, tendrían que resultar cuanto menos comunes a todas ellas. Se trata de valores consensuados que no rompan con la estructura axiológica propia de la sociedad receptora, pero que tampoco ofendan al sentir específico de los recién llegados a ella. En este sentido, nada mejor que recordar el propio carácter universal del derecho a la identidad cultural, que lógicamente protege modos de ser y manifestaciones diferentes porque igualmente diferentes son los presupuestos culturales que cada uno asume en el propio ejercicio del derecho que le corresponde a la identidad cultural. Instando además a la implementación del pluralismo y la diversidad en todas las propuestas educativas, recogiendo las profundas raíces que el multiculturalismo presenta en la sociedad.

Por lo que, se debe fomentar una educación inspirada en la diversidad cultural, considerada como un dato real que enriquece a su vez, por lo que tiene de comprobación de la existencia de modos diferentes de vida, al conjunto del grupo social, una educación enfocada de manera muy particular hacia los miembros de las culturas dominantes para que respeten a la particular idiosincrasia de los grupos minoritarios. Con esta medida se pretende eliminar "el grave riesgo para la autoestima individual que puede surgir en la convivencia entre culturas con posiciones de diferente peso social y capacidad de influencia" ${ }^{42}$.

El objetivo educativo que marca la auténtica realización de la autonomía individual exigirá que la información transmitida sirva para sentar las bases en los estudiantes para que puedan llegar a pensar por sí mismos y poner de manifiesto su espíritu crítico ${ }^{43}$. El proceso educativo deberá para lograrlo, "promover la reflexión sobre los valores y los objetivos que orientan los actuales sistemas educativos, económicos, políticos, religiosos, sociales y culturales; discutir la herencia que las diversas culturas y civilizaciones nos han dejado, y

\footnotetext{
${ }^{40}$ El enunciado 27.2 de la Constitución española de 1978 establece que "La educación tendrá por objeto el pleno desarrollo de la personalidad humana en el respeto a los principios democráticos de convivencia y a los derechos y deberes fundamentales”.

${ }^{41}$ TAJADURA TEJADA, Javier, "El derecho a la cultura como principio rector: multiculturalismo e integración en el Estado Constitucional”, en José Luis CASCAJO CASTRO, Manuel TEROL BECERRA, Antonio DOMÍNGUEZ VILA, Vicente NAVARRO MARCHANTE (coordinadores), Derechos sociales y principios rectores. Valencia: Tirant lo Blanch, 2012, p. 732.

${ }^{42}$ ARA PINILLA, Ignacio. "El impacto jurídico de la diversidad cultural”. Persona y Derecho, Vol. 49, 2003, p. 300.

${ }^{43}$ ENRÍQUEZ SÁNCHEZ, José María; PÉREZ RODRÍGUEZ, Cristina; OTERO LEÓN, Lourdes y FERRARI NIETO, Enrique. Repensar los derechos humanos para una sociedad globalizada. Madrid: Universidad Nacional de Educación a Distancia, 2016, pp. 140-146.
} 
analizar el conocimiento científico y tecnológico actual y su proyección en el futuro" ${ }^{44}$.

El respeto al pluralismo es sobretodo respeto a las personas diferentes que no por ser diferentes dejarán de unirse en un proyecto común de convivencia cuando éste no resulte atentatorio a las exigencias inherentes al respeto de su propia identidad personal. Sostener el carácter destructivo del pluralismo, como muchas veces se hace, es no entender en absoluto su relevante función como único marco aceptable para una realización adecuada de los derechos y libertades de todos.

La educación democrática proporciona las bases sobre las cuales una sociedad democrática podrá "asegurar las libertades políticas y civiles de sus ciudadanos adultos sin poner en riesgo su bienestar o incluso su supervivencia" ${ }^{\text {" }}$. No tendría desde luego sentido pensar en la hipótesis proporcionada por unos individuos que pretendieran destruir de manera irresponsable el instrumento que les proporciona la posibilidad real de ejercer efectivamente sus derechos.

\section{CONCLUSIÓN}

El pluralismo es concebido como uno de los valores que debe inspirar la configuración de las políticas publicas educativas en las sociedades multiculturales. Dentro de un mundo globalizado, en el que nuestra sociedad es cada vez más diversa culturalmente, resulta indispensable garantizar una convivencia pacifica entre personas con diversas identidades culturales. Las políticas educativas que favorecen la integración social y la participación activa de sus miembros, constituye uno de los pilares esenciales de las sociedades democráticas para garantizar el respeto entre las diversas culturas, el consenso social y la paz. Garantizar unos contenidos inspirados en la diversidad cultural dentro de los programas educativos supone una actitud de valoración positiva hacia la interacción entre culturas y la comprensión de lo diverso como un factor de aprendizaje positivo y necesario en las actuales instituciones educativas.

En este sentido, el pluralismo educativo constituye la respuesta a las políticas publicas educativas que conjugue la diversidad cultural con los valores propios de la sociedad receptora. El pluralismo es un valor innato a todo contexto democrático que favorece el intercambio de culturas y su confluencia dentro de un mismo territorio, y que además posibilita el conocimiento de los valores de las diversas culturas y el aprendizaje de las diferentes lenguas. La posibilidad efectiva de acceso al sistema educativo -en términos de igualdad- a aquellos sujetos, que poseen diferentes identidades culturales, es una garantía plena que permite alcanzar la plasmación de un pluralismo entendido como fundamento para integrar los presupuestos de las diferentes culturas dentro de los sistemas educativos en las sociedades multiculturales.

\footnotetext{
${ }^{44}$ OLIVÉ, Leòn. Multiculturalismo y pluralismo. México: Paidós, 1999, p. 26.

${ }^{45}$ GUTMANN, Amy. Op. cit., p. 354.
} 


\title{
PLURALISM AS A FOUNDATION OF MULTICULTURAL EDUCATION
}

\begin{abstract}
An attempt of conceptual approach of the right to education makes us check that their projection can be analysed from a multidimensional aspect, as regardless of the character subjective which account should not be obstacle for eliminate the problems that presents the virtualities of the education. This paper aims to highlight the importance of the universal recognition of the right to education as a tool that must be guaranteed by the State and public policies without any discrimination. Cultural and axiological differentiation presented by multicultural societies is a reality that must be present in any educational project of any democratic society, making it possible to convey possible differences through public policies inspired by educational pluralism.
\end{abstract}

Keywords: Multicultural education. Universality. Educational Pluralism. Axiological values. Cultural diversity.

\section{REFERENCIAS BIBLIOGRÁFICAS}

AGUADO ODINA, María Teresa. Educación multicultural. Su teoría y su práctica, Madrid: UNED, 2008.

ANDER-EGG, Ezequiel. Diccionario de educación. Córdoba, AR: Editorial Brujas, 2014

ARA PINILLA, Ignacio. La difuminación institucional del objetivo del derecho a la educación. Madrid: Dykinson, 2014.

ARA PINILLA, Ignacio. “El impacto jurídico de la diversidad cultural”. Persona y Derecho, Vol. 49, 2003.

AZNAR MINGUET, Pilar.; "Criterios pedagógicos y retos educativos para abordar la integración de inmigrantes en la escuela”. Multiculturalidad escolar y convivencia educativa. Madrid: ECU, 2008.

BELLOSO MARTÍN, Nuria. "El derecho a la educación de los extranjeros en una perspectiva multicultural", en Alfonso DE JULIOS-CAMPUZANO (editor), Ciudadanía y derecho en la era de la globalización. Madrid: Dykinson, 2007.

DE LUCAS, Javier. "El vínculo social, entre ciudadanía y cosmopolitismo". El vínculo social: ciudadanía y cosmopolitismo, Valencia: Tirant lo Blanch, 2002.

EMBID IRUJO, Antonio. "El contenido del derecho a la educación". Revista Española de Derecho Administrativo, núm. 31, 1981.

ENRÍQUEZ SÁNCHEZ, José María; PÉREZ RODRÍGUEZ, Cristina; OTERO LEÓN, Lourdes y FERRARI NIETO, Enrique. Repensar los derechos humanos para una sociedad globalizada. Madrid: Universidad Nacional de Educación a Distancia, 2016.

ESCARBAJAL, A., Interculturalidad, Mediación y trabajo colaborativo, Narcea, Madrid, 2010.

FERNÁNDEZ GARCÍA, Eusebio. "La cultura cívica y los derechos humanos", en Silvina RIBOTTA (editora), Educación en derechos humanos: la asignatura pendiente. Madrid: Dykinson, 2006. 
FERNÁNDEZ-MIRANDA CAMPOAMOR, Alfonso. "Comentarios al artículo 27 CE”. Comentarios a la Constitución Española de 1978. Tomo III. Madrid: Edersa Cortes Generales,1996.

GARCÍA HOZ, Víctor. Diccionario de pedagogía. Barcelona: Labor, 1974.

GARCÍA MARTÍNEZ, Alfonso; ESCARBAJAL FRUTOS, Andrés y ESCARBAJAL DE HARO, Andrés. La interculturalidad. Desafío para la educación. Madrid: Dykinson, 2007.

GUTMANN, Amy. La educación democrática. Una teoría política de la educación, trad. de Águeda Quiroga. Barcelona: Paidós, 2001.

KYMLICKA, Will. "Nacionalismo minoritario dentro de las democracias liberales", en Soledad GARCÍA y Steven LUKES (comps.), Ciudadanía: justicia social, identidad y participación. Madrid: Siglo XXI, 1999.

LEIVA OLIVENCIA, Juan José. Convivencia y educación intercultural: Análisis y propuestas pedagógicas. Alicante: ECU, 2011.

LLAMAZARES FERNÁNDEZ, Dionisio. Educación para la ciudadanía democrática y objeción de conciencia. Madrid: Dykinson, 2009.

LÓPEZ- BARAJAS, Emilio y RUIZ CORBELLA, Marta. Derechos humanos y educación. Madrid: UNED, 2000.

MARTÍNEZ DE PISÓN, José. El derecho a la educación y la libertad de enseñanza. Madrid: Dykinson, 2003.

MARTÍNEZ LÓPEZ-MUÑíZ, José Luis. “La educación en la Constitución española: derechos fundamentales y libertades públicas en materia de enseñanza”. Persona y derecho, núm. 6, 1979.

MUÑOZ ARNAU, Juan Antonio. Derechos y libertades en la política y la legislación educativas españolas. Navarra: Universidad de Navarra, 2010.

NUEVO LÓPEZ, Pablo. La Constitución educativa del pluralismo. Una aproximación desde la teoría de los derechos fundamentales. La Coruña: Netbiblo, 2009.

OLIVÉ, Leòn. Multiculturalismo y pluralismo. México: Paidós, 1999.

OVEJERO LUCAS, Félix. “Como no se debe defender la multiculturalidad”. Letras libres, núm. 13, oct. 2002.

PAREKH, Bhikhu. Repensando el multiculturalismo. Barcelona: Istmo, 2005.

PEIRÓ I GREGÓRI, Salvador. "Multiculturalidad y valores de convivencia educativa”. Multiculturalidad escolar y convivencia educativa. Madrid: ECU, 2008.

PÉREZ SOLA, Nicolás. "Nuevos retos en el ejercicio de los derechos educativos: la incorporación del alumno inmigrante al sistema educativo y la educación en valores", en José Luis CASCAJO CASTRO, Manuel TEROL BECERRA, Antonio DOMÍNGUEZ VILA, Vicente NAVARRO MARCHANTE (coordinadores), Derechos sociales y principios rectores. Valencia: Tirant lo Blanch, 2012. 
ROJAS RIVERO, Gloria Pilar. "El derecho a la educación", en José Luis MONEREO PÉREZ (director) y Luis Ángel TRIGUERO MARTÍNEZ (coordinador), Los derechos de los extranjeros en España. Estudio de la Ley Orgánica 2/2009, de 11 de diciembre, de reforma de la Ley Orgánica 4/2000. Madrid: La Ley, 2010.

SAGASTIZABAL, María de los Ángeles. “Diversidad cultural y educación”, en María Ángeles SAGASTIZABAL (dirección), Diversidad cultural y fracaso escolar. Educación intercultural: de la teoría a la práctica, Madrid: CEP, 2009.

SANTANA RAMOS, Emilia. "Los imperativos culturales como garantía de los derechos del inmigrante". Revista de la Facultad de Derecho, núm. 41, 2016.

SERNA BERMÚDEZ, Pedro. "La dignidad de la persona como principio del derecho público". Derechos y Libertades, núm. 4, 1995.

SOUTO PAZ, José Antonio. "El derecho a la educación”. Boletín de la Facultad de Derecho de la UNED, núm. 1, 1992.

TAJADURA TEJADA, Javier, "El derecho a la cultura como principio rector: multiculturalismo e integración en el Estado Constitucional", en José Luis CASCAJO CASTRO, Manuel TEROL BECERRA, Antonio DOMÍNGUEZ VILA, Vicente NAVARRO MARCHANTE (coordinadores), Derechos sociales y principios rectores. Valencia: Tirant lo Blanch, 2012.

Trabalho enviado em 15 de outubro de 2017.

Aceito em 07 de novembro de 2017. 